\title{
Vildagliptin in renal impairment
}

\author{
Neelesh Dongre $\cdot$ Wolfgang Kothny
}

Received: 14 April 2014/ Accepted: 17 April 2014/Published online: 7 May 2014

(C) Italian Society of Nephrology 2014

\section{Dear Editor-in-Chief,}

We read with interest the article by Schernthaner and Schernthaner [1] entitled "Diabetic nephropathy: new approaches for improving glycemic control and reducing risk", published in the November/December 2013 edition of $J$ Nephrol.

While we commend the authors for highlighting this important topic, we are writing to draw attention to what we believe is potentially misleading information regarding the dipeptidyl peptidase-4 (DPP-4) inhibitor vildagliptin $\left(\right.$ Galvus $\left.^{\circledR}\right)$ in this article. The authors state "Vildagliptin is not recommended for patients with moderate or severe renal impairment ... because of a scarcity of evidence in this setting", citing an earlier paper by Scheen [2]. Although Schernthaner and Schernthaner faithfully quote Dr. Scheen, neither article accurately represents the current labelling for vildagliptin, approved in the European Union and elsewhere, relating to its use in renal impairment.

In fact, the Galvus Summary of Product Characteristics [3] states that vildagliptin may be used at the standard dosage (i.e. $50 \mathrm{mg}$ twice daily) in patients with mild renal impairment $(\mathrm{CrCl} \geq 50 \mathrm{ml} / \mathrm{min})$, and that the recommended dosage for patients with moderate to severe renal impairment, or with end-stage renal disease, is $50 \mathrm{mg}$ once daily.
We are concerned that the authors' statement may lead physicians to either avoid initiating vildagliptin in patients who could potentially benefit from treatment, or, because of unfounded safety concerns, to unnecessarily alter medication in patients who are responding well to vildagliptin.

We believe vildagliptin is an effective treatment option for patients with type 2 diabetes mellitus, and has a favorable benefit:risk ratio in patients with renal impairment when used in accordance with the product labelling.

Conflict of interest WK and ND are employees of Novartis Pharma AG and own shares in the company.

\section{References}

1. Schernthaner G, Schernthaner GH (2013) Diabetic nephropathy: new approaches for improving glycemic control and reducing risk. J Nephrol 26:975-985

2. Scheen AJ (2010) Pharmacokinetics of dipeptidylpeptidase inhibitors. Diabetes Obes Metab 12:648-658

3. Galvus ${ }^{\circledR}$ [Summary of Product Characteristics, EMA, 2013] Novartis Europharm Limited, West Sussex. http://www.ema. europa.eu/docs/en_GB/document_library/EPAR_-_Product_Infor mation/human/000771/WC500020327.pdf. Accessed 29 Jan 2014 